\title{
Studies on the Intestinal Absorption of Low Molecular Weight Heparin Using Saturated Fatty Acids and Their Derivatives as an Absorption Enhancer in Rats
}

\author{
Saori Mori, ${ }^{*}, a$ Akihiro MatsuUra, ${ }^{a}$ Yarasani Venkata RAma Prasad, ${ }^{b}$ and Kanji TAKAdA ${ }^{b}$ \\ ${ }^{a}$ Shimizu Research Center, Shimizu Pharmaceutical Co., Ltd.; 649-1 Shimizu Miyakami, Shizuoka 424-0911, Japan: and \\ ${ }^{b}$ Department of Pharmacokinetics, Kyoto Pharmaceutical University; 5 Nakauchi Misasagi, Yamashina-ku, Kyoto \\ 607-8414, Japan. Received September 10, 2003; accepted December 8, 2003
}

Intestinal absorption of low molecular weight heparin (LMWH) as well as unfractionated heparin (UFH) is limited due to its large molecular size and extensive negative charge. Development of its oral formulations would allow outpatient treatment with LMWH and UFH, and contribute a reduction in hospital expenses. The present study was aimed at evaluating the absorption enhancers Labrasol ${ }^{\mathrm{TM}}$ and Gelucire $44 / 14^{\mathrm{TM}}$, which mainly consist of glycerides and fatty acids esters, to improve the intestinal absorption of LMWH. The absorption effects of saturated fatty acids with several carbon chain lengths $(\mathrm{C6}-\mathrm{C14})$ were also investigated. LMWH formulated with or without absorption enhancer was administered to the duodenum of fasted rats. The doses of LMWH and absorption enhancer were $20 \mathrm{mg} / \mathrm{kg}$ and $30 \mathrm{mg} / \mathrm{kg}$, respectively. Plasma anti-Xa activity was measured as a marker of the LMWH absorption. By administration of the LMWH formulation with Labrasol but not with Gelucire 44/14, the plasma anti-Xa activity was increased to a level above $0.2 \mathrm{IU} / \mathrm{ml}$ which is the critical level for elucidation of its anticoagulant activity. Saturated fatty acids also enhanced the intestinal absorption of LMWH, and the order of absorption-enhancing effect was $\mathrm{C10}=\mathrm{C12}>\mathrm{C14}>\mathrm{C16}>\mathrm{C8} \geq \mathrm{C6}$. These results suggest that the intestinal absorption of LMWH varies with carbon chain lengths of the saturated fatty acids.

Key words low molecular weight heparin; absorption enhancer; saturated fatty acid; anticoagulant; oral heparin

In many countries low molecular weight heparins (LMWHs) have been used for the prevention and treatment of venous thrombo-embolism ${ }^{1)}$ and to replace unfractionated heparin (UFH), due primarily to their longer half-lives and less bleeding properties for a given antithrombotic effect. The main disadvantage of LMWHs, however, is that treatment is limited to parenteral administration alone because of its large molecular weight, negatively charged structure and instability under acidic conditions, such as in the stomach, to which they first are exposed after oral administration. The availability of oral LMWH formulations would result in shortened hospital stay, improvement of patient compliance and reduction in expenses, which cannot be resolved with parenteral formulations. Different strategies are under investigation to improve intestinal absorption of LMWHs. The carrier compound, sodium $N$-[10-(2-hydroxybenzoyl)amino] decanoate (SNAD), was found to increase the enteral absorption of LMWH in experimental animals. ${ }^{2)}$ Intestinal absorptions of LMWH have previously been reported by the use of absorption enhancers, e.g. rectal administration with sodium cholate in rats and human subjects, ${ }^{3)}$ duodenal administration with Carbopol 934P in rats and pigs, ${ }^{4)}$ intestinal administration with chitosan derivatives or mono- $N$-carboxymethyl chitosan in rats. ${ }^{5)}$ Other nonparenteral routes such as nasal ${ }^{6)}$ and transdermal ${ }^{7)}$ routes are also being explored.

Our earlier studies showed that some pharmaceutical additives including surfactants, sodium caprate, bile acid, salicylate and a chelating agent enhanced the intestinal absorption of LMWH in rats. Here, our attention was focused on the commercially available surfactants Labrasol and Gelucire $44 / 14$ as the absorption enhancers, because they have been shown to greatly improve the bioavailability of poorly absorbable drugs such as gentamicin, ${ }^{8)}$ insulin, ${ }^{9)}$ vancomycin, ${ }^{10)}$ albendazole ${ }^{11)}$ and LTB4 inhibitors. ${ }^{12)}$ Labrasol and Gelucire 44/14 are well-defined mixtures of mono-, di- and triglyc- erides and mono- and di-fatty esters of polyethylene glycol, which contain predominant fatty acids composed of caprylate/caprate and laurate, respectively. These fatty acids, caprylate and caprate, are contained in the molecules of sodium $N$-[8-(2-hydroxybenzoyl)amino] caprylate (SNAC) and SNAD, respectively, and are considered to be one of the factors responsible for enhancing the intestinal absorption of $\mathrm{UFH}^{13)}$ and $\mathrm{LMWH}^{2}{ }^{2}$

In the present work, we studied (1) the intestinal absorption of LMWH using Labrasol and Gelucire 44/14 in rats; (2) if one or both of them exhibit such an activity, further study will be conducted to determine which saturated fatty acid is the most effective to enhance the intestinal absorption of LMWH.

\section{MATERIALS AND METHODS}

Animals Male Wistar rats (Nippon SLC, Hamamatsu, Japan) weighing 370 to $420 \mathrm{~g}$ were used. The animals were housed at a constant temperature of $23 \pm 3{ }^{\circ} \mathrm{C}$ with a humidity of $55 \pm 15 \%$ under an automatically controlled $12 \mathrm{~h}$ lightdark cycle (lights on at 7:00 a.m., off at 7:00 p.m.) and had free access to food and water. Acclimatization for the animals was allowed for at least $4 \mathrm{~d}$ before an experiment and they were fasted overnight for at least $12 \mathrm{~h}$ prior to the examination. All animals received humane care in compliance with the "Law Concerning the Protection and Control of Animals" and "Standards Relating to the Care and Management of Experimental Animals".

Materials LMWH [Parnaparin sodium, anti-Xa activity: $85.4 \mathrm{IU}(\mathrm{aXa}) / \mathrm{mg}$ ] was purchased from OPOCRIN (Modena, Italy). Labrasol and Gelucire 44/14 (Gattefösse, France) were obtained from Chugai Boyeki Co., Ltd. (Tokyo, Japan). Sodium caproate (C6), and laurate (C12) and palmitate (C16) were purchased from SIGMA-ALDRICH Japan Co., Ltd. 
(Tokyo). Sodium caprylate (C8), caprate (C10) and myristate (C14) were purchased from WAKO Pure Chemical Industries, Ltd. (Tokyo). All materials used including those not specified here were of reagent grade.

LMWH Preparations To $20 \mathrm{mg}$ (1700 IU) of LMWH dissolved in $1 \mathrm{ml}$ of deionised water, $30 \mathrm{mg}$ of absorption enhancer was added and then mixed well until a transparent formulation was obtained.

Absorption Studies The rats were anesthetized by diethyl ether. The abdominal cavity was opened to isolate the upper small intestine. The LMWH formulation was administered into the duodenum through a small pore with a $25 \mathrm{G}$ needle at doses of $20 \mathrm{mg} / \mathrm{kg}$ of LMWH and $30 \mathrm{mg} / \mathrm{kg}$ of absorption enhancers in a volume of $1 \mathrm{ml} / \mathrm{kg}$. For comparison, LMWH solution without absorption enhancer was introduced into the duodenum at a dose of $20 \mathrm{mg} / \mathrm{kg}$. LMWH solution was also injected subcutaneously (s.c.) at a dose of $2 \mathrm{mg} / \mathrm{kg}$. Three to five rats were used for each group.

Blood samples $(0.54 \mathrm{ml}$ each) were obtained from the jugular vein at 0 (before administration), 15, 30, 60, and $120 \mathrm{~min}$ after the administration, collected in syringes and poured into microtubes containing $0.06 \mathrm{ml}$ of $3.2 \% \mathrm{w} / \mathrm{v}$ trisodium citrate dihydrate solution as an anticoagulant. The samples were mixed well and immediately cooled on an ice bath. Plasma was obtained from whole blood by centrifugation at $12000 \mathrm{rpm}$ for $5 \mathrm{~min}$ at $4{ }^{\circ} \mathrm{C}$ using a Kubota 3700 centrifuge (Tokyo), and then stored at $4{ }^{\circ} \mathrm{C}$ until analysis.

Anti-Xa activity was measured in plasma samples by the Testzym ${ }^{\circledR}$ Heparin S Kit (Daiichi Pure Chemicals Co. Ltd., Tokyo) using the autoanalyzer COBAS MIRA plus (Roche Diagnostics K. K., Tokyo).

Pharmacodynamic Analysis The time to reach maximum plasma anti-Xa activity (Tmax) and the maximum plasma anti-Xa activity ([aXa]max) were determined from the authentic plasma anti-Xa activity $v s$. time data. The area under the plasma anti-Xa activity $v s$. time curve up to 120 min $\left(A U C_{0-2 \mathrm{~h}}\right)$ after administration of the test preparations was calculated using the trapezoid rule.

\section{RESULTS}

The Absorption-Enhancing Effects of Labrasol and Gelucire 44/14 The plasma anti-Xa activity was negligible following the administration of LMWH solution alone (negative control) to the duodenum (Fig. 1). In contrast, when
LMWH was given s.c. (positive control), plasma anti-Xa activity was dramatically increased (Fig. 1), and its [aXa]max and Tmax values were $1.31 \pm 0.05 \mathrm{IU} / \mathrm{ml}$ and $54.0 \pm 6.0 \mathrm{~min}$, respectively. The increased anti-Xa activity was maintained over $0.8 \mathrm{IU} / \mathrm{ml}$ for at least $120 \mathrm{~min}$ (Fig. 1).

Labrasol enhanced the intestinal absorption of LMWH as evidenced by an increased plasma anti-Xa activity (Fig. 1) with a [aXa]max value of $0.32 \pm 0.08 \mathrm{IU} / \mathrm{ml}$, which is considered to be a level adequate to exert anti-coagulant activity in plasma, and with the Tmax value of $15.0 \pm 0.0 \mathrm{~min}$ (Table 1), while Gelucire 44/14 did not (Fig. 1).

The Absorption-Enhancing Effects of Saturated Fatty Acids (C6 to C14) Among saturated fatty acids, the highest [aXa]max value $(1.45 \pm 0.28 \mathrm{IU} / \mathrm{ml})$ was obtained when the $\mathrm{C} 10$ formulation was administered (Table 1). C6 and C8 formulations scarcely increased the plasma anti-Xa activity (Fig. 2a). The Tmax values obtained after administration of $\mathrm{C} 10, \mathrm{C} 12, \mathrm{C} 14$ and $\mathrm{C} 16$ formulations ranged from 15 to $30 \mathrm{~min}$. The order of $A U C_{0-2 \mathrm{~h}}$ values obtained was $\mathrm{C} 10=$ C12 $>$ C14 $>$ C16 $>$ Labrasol $>$ C $8 \geq$ Gelucire 44/14=C6 (Fig. 2b, Table 1). C10, C12 and C14 formulations maintained the plasma anti-Xa activities of more than $0.2 \mathrm{IU} / \mathrm{ml}$ for at least $120 \mathrm{~min}$ (Fig. 2a).

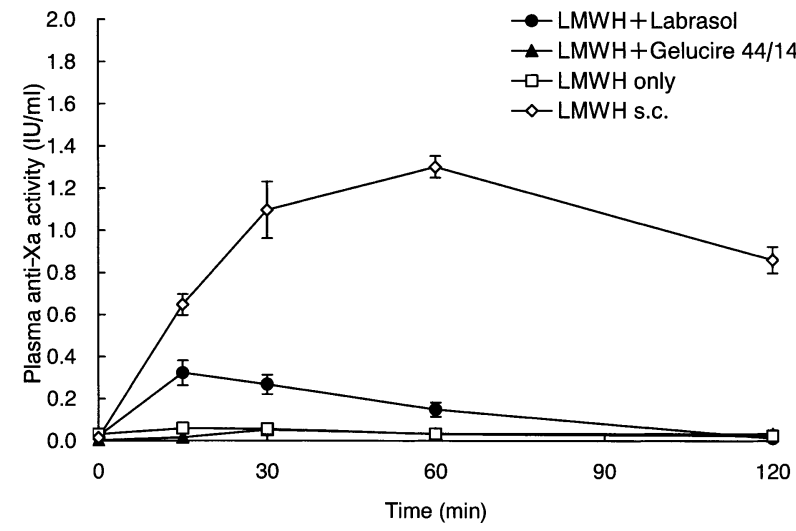

Fig. 1. Changes of Plasma Anti-Xa Activities after Intraduodenum Administration of LMWH $(20 \mathrm{mg} / \mathrm{kg})$ with or without Absorption Enhancer $(30 \mathrm{mg} / \mathrm{kg}$ ), and after Subcutaneous (s.c.) Administration of LMWH $(2 \mathrm{mg} / \mathrm{kg})$ in Rats

Each point represents the mean \pm S.E. of 3 to 5 rats.

Table 1. Pharmacodynamic Parameters of LMWH after Duodenum Administration of a Variety of LMWH Formulations

\begin{tabular}{|c|c|c|c|c|c|}
\hline $\begin{array}{c}\text { Absorption } \\
\text { enhancer }\end{array}$ & $\begin{array}{c}\text { Dose of LMWH } \\
(\mathrm{mg} / \mathrm{kg})\end{array}$ & $\begin{array}{c}\text { Site of } \\
\text { administration }\end{array}$ & $\begin{array}{c}{[\mathrm{aXa}] \max } \\
(\mathrm{IU} / \mathrm{ml})\end{array}$ & $\begin{array}{l}\text { Tmax } \\
(\min )\end{array}$ & $\begin{array}{l}A U C_{0-2 \mathrm{~h}} \\
(\mathrm{IU} \cdot \mathrm{h} / \mathrm{ml})\end{array}$ \\
\hline $\begin{array}{l}\text { Labrasol } \\
\text { Gelucire 44/14 }\end{array}$ & 20 & Duodenum & $\begin{array}{l}0.32 \pm 0.08 \\
0.11 \pm 0.06\end{array}$ & $\begin{array}{l}15.0 \pm 0.0 \\
40.0 \pm 10.0\end{array}$ & $\begin{array}{l}0.30 \pm 0.07 \\
0.07 \pm 0.05\end{array}$ \\
\hline $\begin{array}{l}\text { Caproate }(\mathrm{C} 6) \\
\text { Caprylate }(\mathrm{C} 8) \\
\text { Caprate }(\mathrm{C} 10) \\
\text { Laurate }(\mathrm{C} 12) \\
\text { Myristate }(\mathrm{C} 14) \\
\text { Palmitate }(\mathrm{C} 16)\end{array}$ & 20 & Duodenum & $\begin{array}{l}0.04 \pm 0.02 \\
0.11 \pm 0.04 \\
1.45 \pm 0.28 \\
1.35 \pm 0.22 \\
0.94 \pm 0.17 \\
0.46 \pm 0.04\end{array}$ & $\begin{array}{l}50.0 \pm 35.0 \\
50.0 \pm 35.0 \\
18.0 \pm 3.0 \\
27.0 \pm 3.0 \\
15.0 \pm 0.0 \\
25.0 \pm 5.0\end{array}$ & $\begin{array}{l}0.05 \pm 0.03 \\
0.12 \pm 0.04 \\
1.69 \pm 0.34 \\
1.73 \pm 0.27 \\
1.11 \pm 0.17 \\
0.57 \pm 0.08\end{array}$ \\
\hline- & $\begin{array}{r}20 \\
2\end{array}$ & $\begin{array}{l}\text { Duodenum } \\
\text { Subcutaneous }\end{array}$ & $\begin{array}{l}0.08 \pm 0.01 \\
1.31 \pm 0.05\end{array}$ & $\begin{array}{l}55.0 \pm 32.8 \\
54.0 \pm 6.0\end{array}$ & $\begin{array}{l}0.07 \pm 0.01 \\
1.98 \pm 0.07\end{array}$ \\
\hline
\end{tabular}


(a)

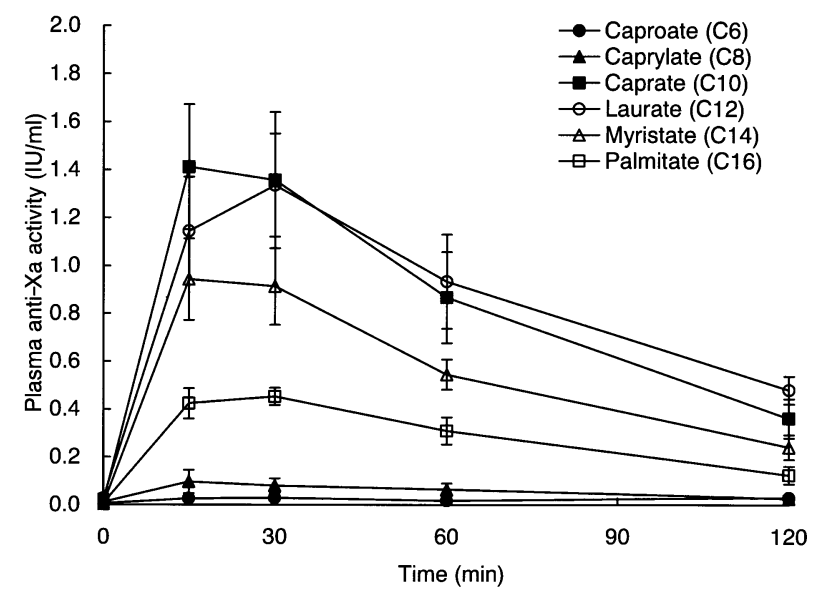

(b)

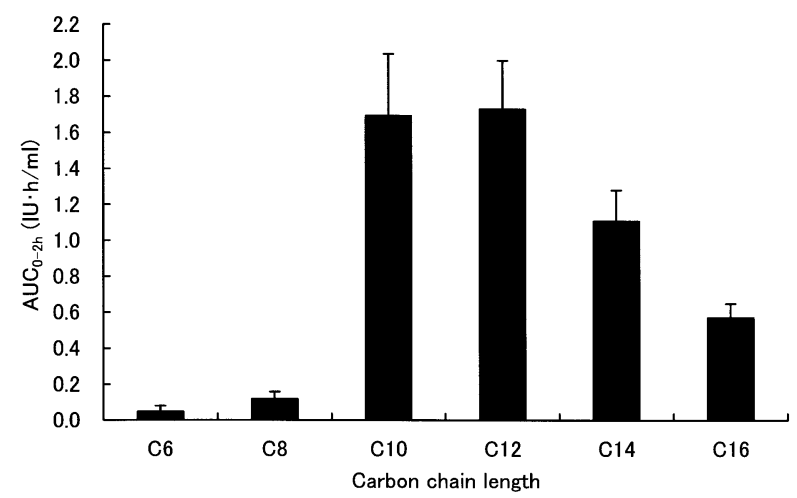

Fig. 2. (a) Effect of Sodium Saturated Fatty Acids (C6-C14) $(30 \mathrm{mg} / \mathrm{kg})$ on the Intestinal Absorption of LMWH $(20 \mathrm{mg} / \mathrm{kg})$ in Rats

Each point represents the mean \pm S.E. of 3 to 5 rats.

(b) The $A U C_{0-2 \mathrm{~h}}$ after Intraduodenum Administration of LMWH $(20 \mathrm{mg} / \mathrm{kg})$ with Saturated fatty Acids $(\mathrm{C} 4-\mathrm{C} 16)(30 \mathrm{mg} / \mathrm{kg})$ in Rats

Each bar represents the mean \pm S.E. of 3 to 5 rats.

\section{DISCUSSION}

Highly hydrophilic macromolecular drugs are thought to be predominantly absorbed through the paracellular but not transcellular pathway; however the transport of such macromolecules through the paracellular pathway is limited by the intestinal barrier, i.e. the tight junction. ${ }^{14)}$ Low molecular weight drugs with high water-solubility can easily pass through the lipid bilayer membrane of the enterocytes. Although LMWH is a highly water-soluble drug, it cannot pass through such membrane pores due to its relatively large molecular weight $(5500 \mathrm{Da})$ and potent negative charges. One approach to overcome the poor membrane permeability of such a drug is to co-administer it with absorption enhancers. The aim of this study was to evaluate the feasibility of the intestinal absorption of a hydrophilic drug, LMWH, in combination with absorption enhancers in rats.

Labrasol and Gelucire 44/14, commercially available absorption enhancers with low toxicity, are a well-defined mixture of mono-, di-, and triglycerides and di-fatty esters of polyethylene glycol. Labrasol contains saturated polyglycolysed C6 - C14 glycerides and their predominant fatty acids are C8-C10, while Gelucire 44/14 contains saturated polyg- lycolysed C8 - C18 glycerides and its predominant fatty acid is C12. Thus the difference between Labrasol and Gelucire $44 / 14$ is the carbon chain lengths of the predominant fatty acids included in their molecular structures. Both reagents make super microemulsions under physiological condition at $37^{\circ} \mathrm{C}$, resulting in great improvement of the bioavailability of hydrophobic drugs as well as hydrophilic drugs. The mechanisms of these reagents are believed to include not only solubility enhancement through micellar formation but also probably absorption enhancement onto the enterocytes. However, the detailed mechanisms have not been well understood. One of the proposed mechanisms was based on the changes of the membrane structure and fluidity by the enhancers, resulting in significant permeability changes. ${ }^{15)}$ This surfactant-induced change in intestinal permeability is correlated with acute epithelial damage, as evidenced by release of cellular components from damaged intestinal epithelium which is attributable to the surfactants. ${ }^{16,17)}$ On the other hand, the toxicity of Labrasol and Gelucire 44/14 is very low, with Labrasol especially being quite safe because of its $\mathrm{LD}_{50}$ value of $22 \mathrm{~g} / \mathrm{kg}$ in rats. In the present study, we first focused on the efficiency of Labrasol and Gelucire 44/14 to enhance the intestinal absorption of LMWH as a water-soluble and poorly absorbable drug.

As generally known, the administration of LMWH alone to the duodenum resulted in a negligible level of plasma anti$\mathrm{Xa}$ activity, indicating its restricted intestinal absorption by the barrier function of the intestinal epithelium. In contrast, concomitant administration of LMWH with Labrasol, but not with Geucire 44/14, into the duodenum rapidly increased the intestinal absorption of LMWH in rats, in which plasma anti$\mathrm{Xa}$ activity was increased with a [aXa]max value of $0.32 \pm$ $0.08 \mathrm{IU} / \mathrm{ml} 15 \mathrm{~min}$ after the administration; then the activity gradually decreased and returned to the pre-dose value at 120 min. Thus, it was shown that Labrasol having a medium length fatty acid carbon chain facilitated the transport of LMWH through the intestinal mucosal barrier.

We speculated that the difference in the absorption-enhancing effect between Labrasol and Gelucire 44/14 was ascribable to the carbon chain lengths of saturated fatty acids contained in them. Among saturated fatty acids, C10 has been reported to have an absorption-enhancing effect on a hydrophilic compound by opening the tight junction as well as by pertubing the fluidity of the brush border membrane, thereby leading to the increase in LMWH absorption through the paracellular pathway. ${ }^{18)}$ Two 2-hydroxybenzoyl derivatives, SNAC having 8 carbon chain lengths and SNAD having 10 carbon chain lengths, have been developed by Emisphere Technology as synthesized delivery agents for $\mathrm{UFH}^{2)}$ and $\mathrm{LMWH},{ }^{16)}$ respectively. In those two derivatives, C8C10 might be the most suitable carbon chain length to enhance the absorption of UFH as evidenced by an increase in APTT. ${ }^{19)}$ Therefore, we evaluated the saturated fatty acids with several carbon chain lengths, which is thought to be one of the factors enhancing intestinal absorption of LMWH, in order to determine the optimal carbon chain length.

In contrast to our expectation, the plasma anti-Xa activity was hardly increased with C6 and C8 formulations. When the carbon chain length was increased to $\mathrm{C} 10$ or $\mathrm{C} 12$, the plasma anti-Xa activity was markedly increased over 1.0 $\mathrm{IU} / \mathrm{ml}$ and then decreased with the increase in length to C14 
and $\mathrm{C} 16$. The order of total increase in plasma anti-Xa activity, $A U C_{0-2 \mathrm{~h}}$, was $\mathrm{C} 10=\mathrm{C} 12>\mathrm{C} 14>\mathrm{C} 16>\mathrm{C} 8 \geq \mathrm{C} 6$ (Fig. 2). As it has been reported that the plasma anti-Xa activity required for obtaining a $50 \%$ antithrombotic effect is 0.12 $\mathrm{IU} / \mathrm{ml},{ }^{20)}$ adequate antithrombotic activity would be obtained by the administration of LMWH with $\mathrm{C} 10-\mathrm{C} 14$, by which plasma anti-Xa activities were maintained at more than 0.2 $\mathrm{IU} / \mathrm{ml}$ for $120 \mathrm{~min}$. These results suggest that there are optimum carbon chain lengths for LMWH absorption, and that the medium chain saturated fatty acids $\mathrm{C} 10$ and $\mathrm{C} 12$ had the most potent absorption-enhancing effects.

Compared with the saturated fatty acids, the intestinal absorption-enhancing effects of Labrasol and Gelucire 44/14 on LMWH, in spite of containing saturated fatty acids (C10 - C16), were less than that of saturated fatty acids having $\mathrm{C} 10-\mathrm{C} 16$. The diminution of the absorption-enhancing effects of Labrasol and Gelucire 44/14 is probably attributable to their formulations mixed with mono-, di- and triglycerides and mono- and di-fatty esters. Especially with Gelucire 44/14, the effect was found to be much weaker than that of Labrasol probably due to not only the difference in fatty acid composition but the physicochemical difference of their solutions, such as microemulsion formation.

In conclusion, saturated fatty acids having the carbon chain lengths of $\mathrm{C} 10-\mathrm{C} 16$, especially $\mathrm{C} 10$ and $\mathrm{C} 12$, exhibited potent enhancement of the absorption of LMWH from the rat small intestine. Furthermore, fatty acid moiety with such a carbon chain length contained in the Labrasol molecule would contribute in part to its activity to enhance intestinal absorption of LMWH.

Acknowledgements We are grateful to Dr. N. Akaike, Mr. K. Kamiya, Mr. D. Nishinaka, Mr. T. Furuya and Ms. N. Matsutani of Shimizu Pharmaceutical Co., Ltd. for kindly providing their experimental support.

\section{REFERENCES}

1) Boneu B., Thromb. Res., 100, V113-V120 (2000).

2) Salartash K., Lepore M., Gonze M. D., Leon-bay A., Baughman R., Sternbergh W. C., III, Bowen J. C., Money S. R., Ann. Surg., 231, 789-794 (2000).

3) Nissan Ziv E., Kidron M., Bar-On H., Friedman G., Hyam E., Eldor A., Haemostasis, 30, 225-232 (2000).

4) Thanou M., Verhoef J. C., Nihot M. T., Verheijden J. H. M., Junginger H. E., Pharm. Res., 18, 1638-1641 (2002).

5) Thanou M., Nihot M. T., Jansen M., Verhoef J. C., Junginger H. E., J. Pharm. Sci., 90, 38-46 (2001).

6) Arnold J., Ahsan F., Meezan E., Pillion D. J., J. Pharm. Sci., 91, 1707-1714 (2002).

7) Mitragotri S., Kost J., Pharm. Res., 18, 1151-1156 (2001).

8) Hu Z., Tawa R., Konishi T., Shibata N., Takada K., Life Sci., 69, 2899-2910 (2001).

9) Eaimtrakarn S., Rama Prasad Y. V., Ohno T., Konishi T., Yoshikawa Y., Shibata N., Takada K., J. Drug Target, 10, 255-260 (2002).

10) Rama Prasad Y. V., Puthli S. P., Eaimtrakarn S., Ishida M., Yoshikawa Y., Shibata N., Takada K., Int. J. Pharmaceut., 250, 181-190 (2003).

11) Savio E., Dominguez L., Malangra A., Quevedo D., Saldana J., Camarote C., Ochoa A., Fagiolino P., Boll. Chim. Farm., 137, 345-349 (1998).

12) Hauss D. J., Fogal S. E., Ficorilli J. V., Price C. A., Roy T., Jayaraj A. A., Keirns J. J., J. Pharm. Sci., 87, 164-169 (1998).

13) Rivera T. M., Leone-Bay A., Paton D. R., Leipold H. R., Baughman R. A., Pharm. Res., 14, 1830-1834 (1997).

14) Madara J. L., J. Clin. Invest., 83, 1089-1094 (1989).

15) Swenson E. S., Curatolo W. J., Adv. Drug Deliv. Rev., 8, 39-92 (1992).

16) Uchiyama T., Sugiyama T., Quan Y.-S., Kotani A., Okada N., Fujita T., Muranishi S., Yamamoto A., J. Pharm. Pharmacol., 51, 1241-1250 (1999).

17) Muranishi S., Yakugaku Zasshi, 117, 394-414 (1997).

18) Shimazaki T., Tomita M., Sadahiro S., Hayashi M., Awazu S., Dig. Dis. Sci., 43, 641-645 (1998).

19) Leone-Bay A., Paton D. R., Freeman J., Lercara C., O’Toole D., Gschneidner D., Wang E., Harris E., Rosado C., Rivera T., DeVincent A., Tai M., Mercogliano F., Agarwal R., Leipold H., Baughman R. A., J. Med. Chem., 41, 1163-1171 (1998).

20) Bianchini P., Bergonzini G. L., Parma B., Osima B., Haemostasis, 25, 288-298 (1995). 